\section{Alllu 97081 I} NBS1F $88-3743$

\section{NIST \\ PUBLICATIONS}

\title{
INTEGRATED MANUFACTURING DATA ADMINISTRATION SYSTEM (IMDAS) OPERATIONS MANUAL
}

Aprit 21. 1988

By.

Beborah A. Nickerson:
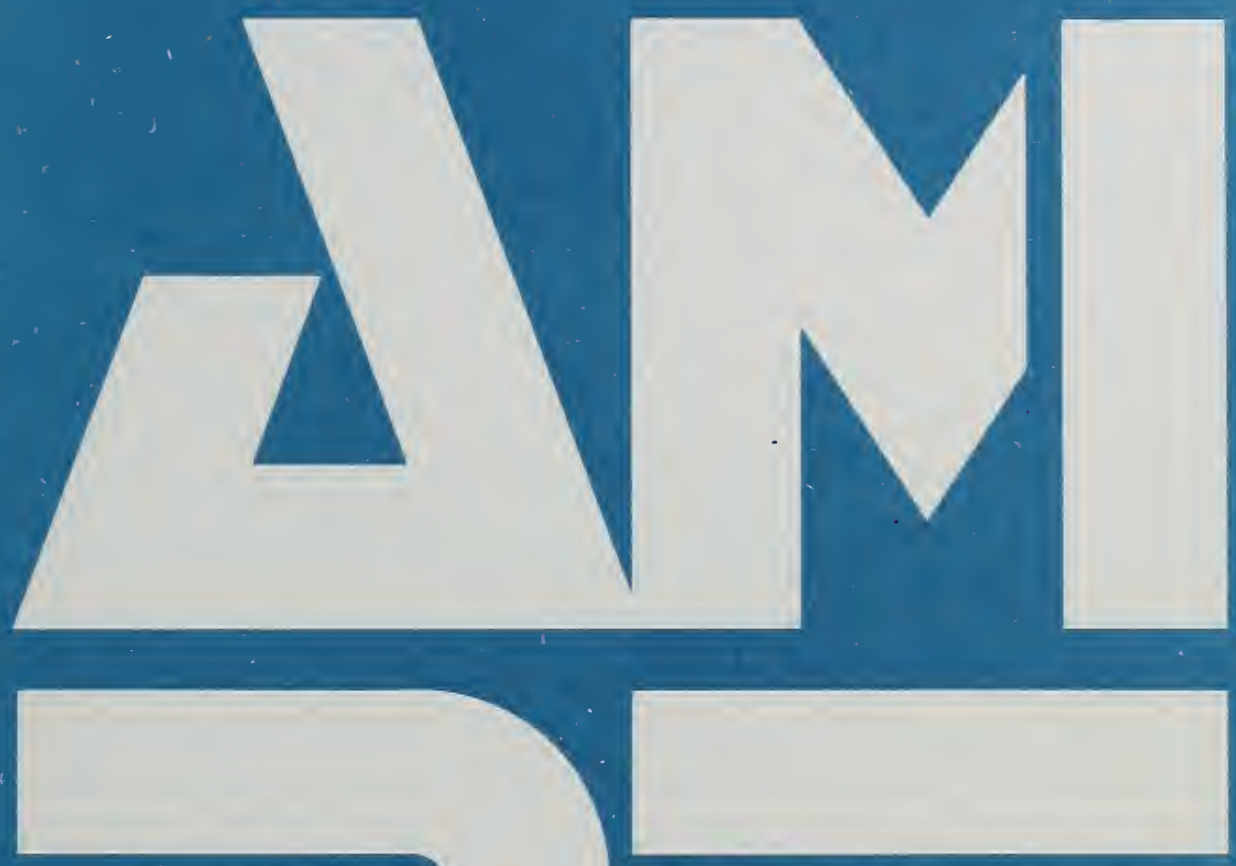

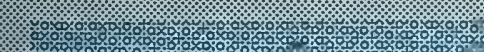
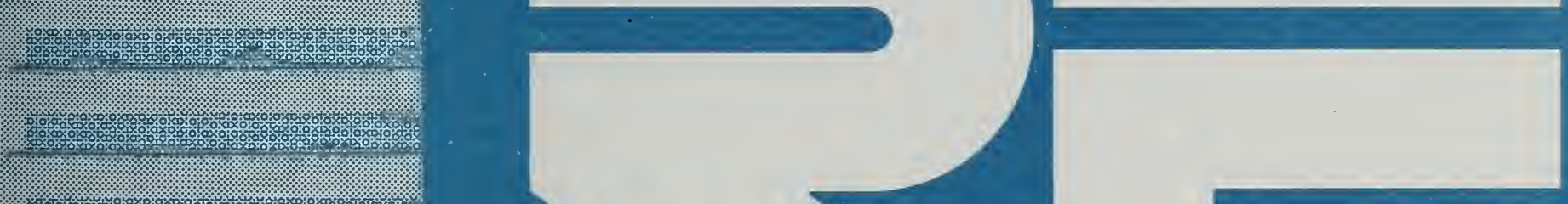

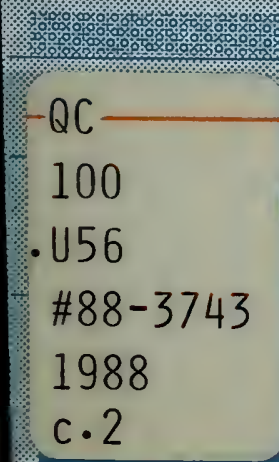


NATIONAL MSTITUTE OF STANDARDS \&

THCHOLOG

Research Thatormation Center

Gaitherswurg, MD 20899 


\title{
INTEGRATED MANUFACTURING DATA ADMINISTRATION SYSTEM OPERATIONS MANUAL
}

\author{
Deborah A. Nickerson \\ Integrated systems Group \\ Factory Automation Systems Division \\ National Bureau of Standards
}

Apri I 21, 1988

\section{DISCLAIMER}

Certain commercial equipment, instruments, or materials are identied in this paper in order to adequately specify the experimental procedure. Such identification does not imply recommendation or endorsement by the National Bureau of Standards, nor does it imply that the materials or equipment identied are necessarily the best available for the purpose.

This publication was prepared by United States Government employees as part of their official duties and is, therefore, a work of the U.S. Government and not subject to copyright. 
I. Introduction

1. Purpose of This Document

2. Modes of Operation

3. Contacts for Errors

4. Conventions Used in This Document

4.1. Keyboard Conventions

4.1.1. Carriage Return

4.1.2. Delete

4.2. Sun References

4.3. VAX References

4.4. NETWORK References

I1. Devices Needed
1 .
Foreground Mode
2 .
Background Mode

111. Foreground Mode

$4-6$
1. Sun startup
1.1. Lockscreen Mode
1.2. Power of $f$
2. Login
3. IMDAS startup
4. Connecting AMRF systems
5. Bringing Down the IMDAS
6. Logging out
6. 1. Logging out Connections to the VAX
6.2. Logging out of the IMDAS sun Account

IV. Background Mode
1. Login
2. Enter IMDAS Directory
3. Background Startup
4. Start Operator Interface
5. Connecting AMRF systems
6. Bringing Down the IMDAS
7. Logging out

V. Database Mai Ibox Prefixes
1. Horizontal Workstation
2. Inspection Workstation
3. Cell
4. Vertical Workstation 
5. Cleaning and Deburring Workstation

6. Material Handling Workstation

7. Process Planning

List of References

Reader Comment Form 
INTEGRATED MANUFACTURING DATA ADMINISTRATION SYSTEM OPERATIONS MANUAL

List of Figures

Figure 1. Amrf Floor Layout 
INTEGRATED MANUFACTURING DATA ADMINISTRATION SYSTEM

OPERATIONS MANUAL

1. INTRODUCTION

1. PURPOSE OF THIS DOCUMENT

The purpose of this manual is to provide instructions to train an operator to run Version 1.3 of the Integrated Manufacturing Data Administration system (IMDAS). The IMDAS is an ongoing research effort supporting data access throughout the Automated Manufacturing Research Facility (AMRF) [2].

2. MODES OF OPERATION

The mode generally used during operation of the IMDAS is the Foreground mode; this mode gives the operator a more visual layout of the IMDAS. The Background mode is available should a sun workstation not be in service.

3. CONTACTS FOR ERRORS

If the operator encounters any error, he/she should contact one of the principal operators/researchers of the Integrated systems Group for assistance at $\times 3557$.

4. CONVENTIONS USED IN THIS DOCUMENT

4.1. Keyboard Conventions

4.1.1. Carriage Return

As a general practice, after each command, enter a carriage return <cr>.

$$
\text { 4.1.2. Delete }
$$

In case of a typographical error, use the delete key to erase.

\subsection{Sun References}

Throughout this manual references to a 'Sun workstation' are made. These are aliases for Sun Microsystems and sun Workstations which are trademarks of Sun Microsystems, Inc.

4.3. VAX References

Throughout this manual references to the 'VAX' are made. These are aliases for the CME: :VAX. 
4.4. NETWORK References

Throughout this manual references to the 'NETWORK' system are made. These are al iases for the Automated Manufacturing Research Facility Network System. To run the Network system refer to "AMRF Network Communications" [1]. 
I I. DEVICES NEEDED

The following is a I ist of DEVICES needed for operating the IMDAS in the foreground and Background modes. The DEVICES mentioned below are located in Control Room II of the shops BIdg. (An AMRF floor plan is appended to the back of this manual.)

1. FOREGROUND MODE

A sun microsystem is needed in addition to the NETWORK system.

2. BACKGROUND MODE

A vt100 terminal linked to the VAX $v i a$ a net is needed in addition to the NETWORK system. 


\section{I11. FOREGROUND MODE}

This section describes how to bring up IMDAS in Foreground mode using a sun workstation.

\section{SUN STARTUP \\ 1. 1. Lockscreen Mode}

If the sun is in lockscreen or screen-saver mode ( $i . e$. the background of the screen is blacked out and an icon (picture) is flashing about the screen), press the left mouse button or a key on the keyboard to quit.

\subsection{Power of $f$}

If the sun is completely turned off, turn it on via two main power switches:

(1) Turn the base pedestal switch to position (1).

(2) Turn the terminal (display screen) switch to position ( 1 ).

At this point the sun should be either at a login prompt or rebooting itself. The user will notice a reboot in process if he sees the word "boot" being displayed. Should the SUN get stuck at a question mark (?) during the boot process, an expert should be notified at the number given in section 3 of the Introduction of this manual.

\section{LOGIN}

At the sun login prompt, type 'imdas'.

NOTE: At this point, ask the supervisor or NETWORK operator if the NETWORK is ready for processing. If so, proceed to the next step, IMDAS STARTUP; otherwise, wait until the NETWORK is ready for processing.

\section{IMDAS STARTUP}

The system will give the following prompt:

Do you wish to bring up the VAX imdas? ( $y / n)$

Enter ' $y$ ' to bring up the imdas. 
The IMDAS automatically connects to all the AMRF systems and displays the connected command and status mailboxes for each system in the window labelled 'realuser' (located at the top left of the screen) [1]. To decipher the mailbox names

listed, i.e., (for example):

\section{name: DS PP CMD}

name: DS_PP_STS

look at the mailbox prefix (for the above example - DS_PP) and section $V$, Database Mailbox Prefixes. In the above example, the prefix refers to the Process Planning system.

Note: The IMDAS is ready for transaction interaction when the messages in the windows have stopped scrolling.

5. BRINGING DOWN THE IMDAS

(1) Type $a$ ' $q$ ' at the realuser prompt.

(2) Type 'ex.it' at the VAX DEBUG prompt DBG>.

(3) Move the Sun mouse pointer to each window, except the 'console' window (located at the top right of the screen), and type a '<ctrl-c>' (hold the control key down while depressing the ' $c$ ' character).

(4) Move the sun mouse pointer to each window, except the 'console' window, and type 'exit'.

Note: In the window labelled 'ctgms' (located at the third right of the screen), after the above (4) 'exit' has been typed, type an additional 'exit' at the VAX DEBUG prompt $D B G>$.

6. LOGGING OUT

6.1. Logging out Connections to the VAX

Move the sun mouse pointer to each of the windows, except the 'console' window, and type 'logout'.

All the windows on the screen should vanish except the 'console" window.

\subsection{Logging out of the IMDAS Sun Account}

(1) Move the sun mouse pointer to the gray area. 
(2) While depressing the right mouse button, move the Sun mouse pointer to the 'Basic Tools $\rightarrow$ ' arrow (another menu should pop up), and keeping the right mouse button depressed, move the sun mouse pointer to the 'Exit Suntools' selection on the second menu. Release the button.

The Suntools screen should disappear and the directory prompt:

('machine name') imdas:

should be visible.

(3) Type 'logout'.

The login prompt should now be visible.

6 


\section{BACKGROUND MODE}

This section describes how to bring up IMDAS in BACKGROUND mode using a vt100 terminal.

1. LOGIN

At the VAX login prompt, type AMRFINT1, password AMRF.

2. ENTER IMDAS DIRECTORY

At the directory prompt:

directory (NET, IMDAS, TEKDISP, other):

Type 'imdas' to enter the IMDAS subdirectory.

NOTE: At this point, ask the supervisor or NETWORK operator

if the NETWORK is ready for processing. If so, proceed

to the next step, BACKGROUND STARTUP; otherwise, wait until the NETWORK is ready for processing.

\section{BACKGROUND STARTUP}

Type '@bgimdas amrftst 1 '.

The following processes should be listed, followed by a system prompt (\$):

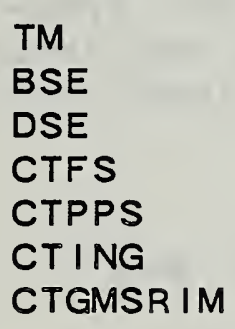

4. START OPERATOR INTERFACE

Type 'run/nodebug realuser'.

The following prompt should be listed:

imdas, connect, read, write, declare, sync, print-style, finish, @file: 


\section{CONNECTING AMRF SYSTEMS}

NOTE: For each AMRF system connection, steps (1) thru (3) must be made.

(1) At the prompt, type ' $c$ ' for connect.

(2) At the mailbox prompt:

mailbox prefix ( $\langle\mathrm{Cr}\rangle$ for "COKE"):

Type the appropriate mailbox prefix.

For example, for Inspection Workstation, the mailbox prefix is: DS IWS. A list of the mailbox prefixes for each workstation is located at the back of this manual in Section V, Database Mailbox Prefixes. Ask the supervisor or NETWORK operator which AMRF systems are to be connected. NOTE: Mailbox prefixes must be typed in CAPITALS.

(3) At the station name prompt:

$$
\text { station name ( }\langle c r\rangle \text { for "VAX"): }
$$

Type a carriage return $<c r>$.

(4) Type 's' for sync.

(5) Type ' $r$ ' for read; this will list back the command and status mailboxes of each AMRF system that has been connected, enabling the operator to check for typographical errors. For example, connecting the Process Planning system with the following mailbox prefix:

$$
\text { DS_PP }
$$

connects the system's appropriate command and status mailboxes:

$$
\text { name: DS_PP_CMD }
$$

name: DS_PP_STS

If an error is discovered, redo steps (1) thru (5) until connection is established.

NOTE: The system is now ready for transaction interaction.

6. BRINGING DOWN THE IMDAS

(1) Type a ' $q$ ' at the realuser prompt. 
(2) At the system prompt, type '@killimdas'. After a short period of time all the processes should vanish.

7. LOGGING OUT

To disconnect the session from the VAX, type 'logout'.

9 
$\checkmark$. DATABASE MAILBOX PREF I XES

This section gives a listing of the Database Mailbox prefixes for each workstation. These are the current prefixes as listed in the November 29, 1986 document of Mailbox Scripts.

1. HORIZONTAL WORKSTATION

Workstation Controller Bucket - DS HWS

Machine Tool Controller Bucket - DS HMTC

Material Buffering Device Bucket - $\bar{D} S$ HMBD

RCS Robot Controller Bucket - DS_HRCS

Vision System Bucket - DS_HVIS

2. INSPECTION WORKSTATION

Workstation Controller Computer - DS IWS

Coordinate Measuring Machine Computer - DS ICMM

Robot Controller Computer - DS IRCS

Surface Roughness Instrument Cömputer - DS_ISRI

3. CELL

Interface - DS_C

4. VERTICAL WORKSTATION

Sun Communications Server - DS_VWS

5. CLEANING AND DEBURRING WORKSTATION

Sun Commications Server - DS_DWS

6. MATERIAL HANDLING WORKSTATION - DS_MHS

7. PROCESS PLANNING - DS_PP 


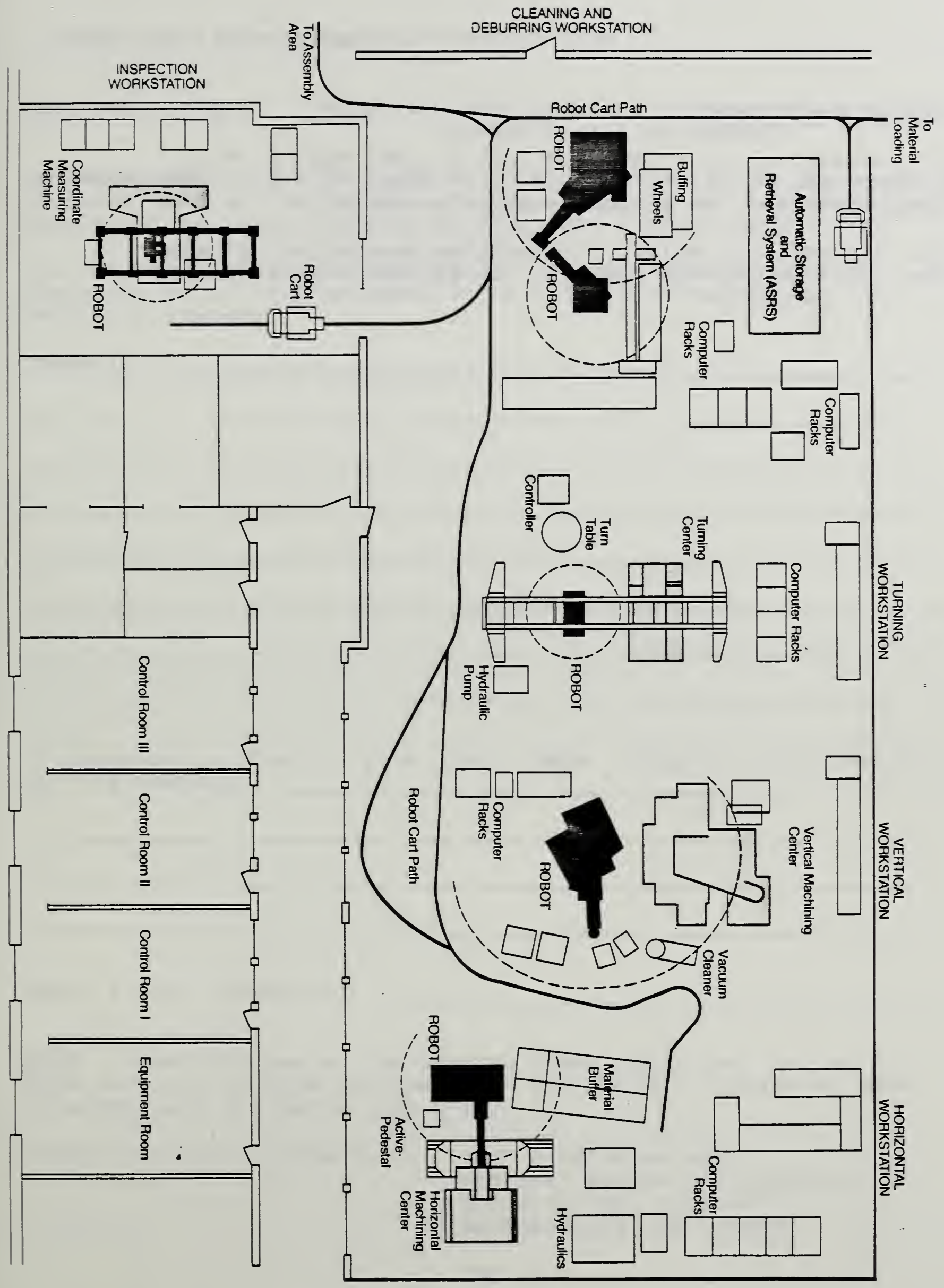

Figure 1. AMRF Floor Layout 


\section{List of References}

[1] Rybczynski, S., Barkmeyer, E. J., Wallace, E. K., Strawbridge, M. L., Libes, D. E., Young, C. V., "AMRF Network Communications", to be published as an NBSIR.

[2] Furlani, C., Editor, "Integrated Manufacturing Data Administration system (IMDAS)", to be published as an NBSIR. 
Document Title

Integrated Manufacturing Data Administration System Operations Manual

This document is one in a series of publications which document research done at the National Bureau of Standards" Automated Manufacturing Research Facility from 1981 through March, 1987.

You may use this form to comment on the technical content or organization of this document or to contribute suggested editorial changes.

Comments :

If you wish a reply, give your name, company, and complete mailing address:

What is your occupation?

NOTE: This form may not be used to order additional copies of this document or other documents in the series. Copies of AMRF documents are available from NTIS.

Please mail your comments to: AMRF Program Manager

National Bureau of Standards

Building 220, Room B-111

Gaithersburg, MD 20899 
U.S. DEPT. OF COMM.

BIBLIOGRAPHIC DATA

SHEET (See in structions)
1. PUBLICATION OR REPORT NO.

NBSIR $88 \div 3743$
2. Performing Organ. Report No 3. Publication Date

APRIL 1988

4. TITLE AND SUBTITLE

Integrated Manufacturing Data Administration System Operations Manual

5. $\operatorname{AUTHOR}(S)$

Deborah A. Nickerson

6. PERFORMING ORGANIZATION (If joint or other than NBS, see instructions)

7. Contract Grant No.

NATIONAL BUREAU OF STANDARDS

DEPARTMENT OF COMMERCE

WASHINGTON, D.C. 20234

8. Type of Report \& Period Covered

9. SPONSORING ORGANIZATION NAME AND COMPLETE ADDRESS (Street, City, Stote, ZIP)

10. SUPPLEMENTARY NOTES

Document describes a computer program; SF-185, FIPS Software Summary, is attached.

11. ABSTRACT (A 200-word or less foctual summary of most significant information. If document includes a significant bibliography or literoture survey. mention it here)

This is an operator's manual for the Integrated Manufacturing Data Administration System (IMDAS) of the Automated Manufacturing Research Facility (AMRF). The IMDAS is designed to provide the control systems of the AMRF access to the data necessary to support the design, planning, manufacturing, and inspection of parts. This manual describes the necessary steps to place the IMDAS into service within the AMRF.

12. KEY WORDS (Six to twelve entries: alphabetical order: capitalize only proper names; and separate key words by semicolons) IMDAS, AMRF, CIM

13. AVAILABILITY

X Unlimited

For Official Distribution. Do Not Release to NTIS

Order From Superintendent of Documents, U.S. Government Printing Office, Washington, D.C. 20402.

Xrder From National Technical Information Service (NTIS), Springfield, VA. 22161
14. NO. OF

PRINTED PAGES

\section{9}

15. Price

$\$ 9.95$ 

